\title{
EL ESPÍRITU OLÍMPICO EN OCCIDENTE DESDE SUS ORÍGENES EN GRECIA Y LOS JUEGOS OLÍMPICOS DE TOKIO (1964-2021)
}

\author{
María del Pilar Garcés García \\ Universidad de Valladolid
}

\section{RESUMEN}

Dada la importancia que ha adquirido el deporte en la sociedad actual y la relevancia futurista que han alcanzado los Juegos Olímpicos de Tokio 2021, el presente estudio se propone centrar su atención en el deporte y las olimpiadas como fenómeno literario y artístico en Japón analizando las principales connotaciones del imaginario japonés en contraste con Occidente. La presentación del trazado histórico-literario en relación con el tema del deporte y las olimpiadas a lo largo de la historia de la literatura supone la constatación de la ingente cantidad de arquetipos que pueden encontrase en el siglo xxI. Todo ello pone de manifiesto, al menos cualitativamente, la importancia del deporte como tema literario, mitológico y artístico entre 1964 y 2020, en los cuales trataremos de centrar nuestra visión crítica y analítica, destacando las principales habilidades literarias utilizadas para inmortalizar este mundial evento, ritualizado desde la época grecolatina. Realizaremos también un análisis del sentido literario y filosófico de las olimpiadas y del atleta olímpico como personaje en la antigüedad occidental y de las olimpiadas y el atleta en la antigüedad nipona, rescatando la evolución ritual y literaria hasta el siglo actual.

Palabras clave: olimpiadas, deporte, literatura, Japón y Occidente.

\section{THE OLYMPIC SPIRIT IN THE WEST FROM ITS ORIGINS IN GREECE AND THE TOKYO OLIMPICS GAMES (1964-2021)}

\section{Abstract}

Given the importance that sport has acquired in today's society and the futuristic relevance that the Olympic Games in Tokyo in 2021 have achieved, this study proposes to focus on sport and the Olympics as a literary and artistic phenomenon in Japan, analyzing the main connotations of the Japanese imaginary, in contrast to the West. The presentation of the historical-literary layout in relation to the theme of sport and the Olympics throughout the history of literature supposes the verification of the enormous amount of archetypes that can be found in the 21st century. All this highlights, at least qualitatively, the importance of sport as a literary, mythological and artistic subject between 1964 and 2020, period on which we will try to focus our critical and analytical vision, highlighting the main literary skills used to immortalize this world event, ritualized since the Greco-Latin era. We will also carry out an analysis of the literary and philosophical meaning of the Olympics and of the Olympic athlete as a character in Western antiquity and of the Olympics and the athlete in Japanese antiquity, rescuing the ritual and literary evolution until the current century.

KeYwords: Olympics, sport, literature, Japan and the West. 


\section{LOS ORÍGENES DE LOS JUEGOS OLÍMPICOS EN OCCIDENTE}

El barón de Coubertin (1863-1937) tenía una idea muy clara de lo que debía comportar la educación: el entrenamiento de la mente y del cuerpo tal y como lo concibieron los antiguos griegos, que tenían como ideal la perfección del cuerpo, el espíritu competitivo y la superación individual. En la Francia que le tocó vivir a Charles Pierre de Frédy, barón de Coubertin, la idea de introducir en el plan de estudios académico la educación física no era algo que se contemplara. El aristócrata francés, fundador del Comité Olímpico Internacional en 1894, mostró durante toda su vida un gran interés por el papel que debía jugar el deporte en la educación de los jóvenes. Para convencer a las autoridades galas de que la educación física era vital en la preparación de la juventud, organizó un viaje a Inglaterra en 1883, donde visitó, entre otros, el colegio de Rugby, que había introducido el deporte en su plan de estudios en 1850. Para el barón, «el deporte organizado puede generar fortaleza moral y física» (Coubertin 1970).

Su concepto del deporte se basa en la idealización del espíritu de los antiguos Juegos Olímpicos griegos, cuyo origen es de culto al dios Zeus. Olimpia, santuario de la deidad, era una ciudad situada en el Peloponeso donde se celebraban las competiciones deportivas para festejar al dios del Olimpo. Parece ser que es en el año 776 a.C. cuando tienen lugar los primeros Juegos Olímpicos, pero no hay fuentes que confirmen esta fecha, ni literarias ni arqueológicas. Durante 12 siglos se siguieron organizando los juegos cada cuatro años hasta que Teodosio los prohibió en el año 393 d.C. porque el cristianismo consideraba que debía darse culto al espíritu y no al cuerpo, además de condenar la organización de los juegos por juzgar que no eran sino la prolongación de prácticas religiosas paganas.

En la antigua Grecia lo importante era ser el vencedor, llegar el primero, ser el mejor y alcanzar la gloria. Solo el ganador recibía como premio una corona de olivo y los segundos o terceros no tenían ningún tipo de reconocimiento, lo que contrasta con el lema de los modernos Juegos Olímpicos, citius, altius, fortius (más rápido, más fuerte, y más alto), que hace referencia al espíritu de superación que debe guiar a todos los deportistas, por lo que se deduce que lo importante no es ganar, sino participar. Fue el fraile dominico francés fray Henri Didon, educador amigo de Coubertin, el que utilizó este famoso lema que aparece en el frontispicio de su colegio, Alberto Magno de París. Sería en 1894, en el primer congreso olímpico, cuando se adoptó este lema para los juegos.

Si bien el término "deporte» no aparece en el vocabulario griego, ya que en general lo hemos tomado prestado del inglés sport, que a su vez procede del latín deportare (destierro, llevar fuera de la ciudad) y semánticamente fue trasladando su significado a salir al campo, respirar aire fresco, distraer la mente y hacer ejercicio, el vocabulario deportivo actual sí deriva de palabras griegas como «atleta»-athletes (el que compite por un premio), "estadio», «disco», «hipód romo", "gimnasio»-gymnasion (lugar donde se hace ejercicio desnudos).

Los Juegos Olímpicos griegos únicamente organizaban competiciones en las siguientes disciplinas: dialus (una carrera alrededor de un estadio), dolichos (una 
carrera de mayor distancia, probablemente dos vueltas a un estadio) y pentatlón (una combinación de cinco pruebas: carrera a pie, lanzamiento de disco, lanzamiento de jabalina, salto de longitud y combate de lucha). El pancracio, posteriormente, fue otro evento competitivo y consistía en una combinación de lucha y boxeo. Los juegos se celebraban cada cuatro años en verano. Los atletas se inscribían a título individual, no representaban a un estado, y eran evaluados por unos jueces que tenían que comprobar que cumplían los cinco requisitos: ser griegos, ser hombres libres, hijos legítimos de padres griegos, no estar privados de derechos de ciudadanía por haber cometido algún delito y haberse entrenado durante un período de diez meses antes de la prueba. A partir del año 724 a.C. algunos atletas corrían desnudos durante la competición y se entrenaban sin protección en los genitales (Pastor 2008). Durante los primeros siglos los participantes de los juegos eran personas que pertenecían a la aristocracia y el deportista competía sin ánimo de lucro, solo lo hacía para demostrar que era el mejor. Llegar a la perfección en el deporte requería mucho tiempo y dinero, y esto solo se lo podía permitir la clase alta, si bien es cierto que, a partir del siglo viI, con la aparición de los hoplitas, el deporte se democratizó y se entrenaban deportistas de las clases bajas. Lo cierto es que los vencedores olímpicos acababan siendo venerados como héroes en los que confluían la historia y la leyenda. Algunos deportistas célebres eran también hombres cultos como Milón de Crotona, que fue discípulo de Pitágoras y en cuya casa murió el matemático. En cuanto a la presencia femenina en los juegos, hay que resaltar que mientras que en Atenas no participaban de forma activa, sí lo hacían las mujeres de Esparta, que entrenaban para competir públicamente en las modalidades de carrera, lucha, lanzamiento de disco y jabalina, pugilismo, natación y equitación. En Olimpia las jóvenes tenían un festival propio, los Juegos Hereos, en honor de la diosa Hera, que también se celebraban cada cuatro ańos, pero tenían prohibido participar en los Juegos Olímpicos, ni como deportistas ni como espectadoras, excepto en las competiciones hípicas como propietarias de caballos.

En cuanto a la relevancia que tenía el deporte en la Grecia antigua, es importante reseñar que, además de ser el deporte una manifestación pública en un espacio abierto tan del gusto de los griegos, supone también una preocupación por mantener un equilibrio entre la perfección del cuerpo y la intelectual, es decir, la kalokagathía. Sin embargo, la educación de la juventud griega no siempre tuvo presente esta doble perfección. Podemos decir que los Juegos Olímpicos tuvieron una edad de oro, donde los deportistas victoriosos eran héroes, que finaliza con la guerra del Peloponeso, cuando los sofistas imponen un modelo educativo en que prima el cultivo del intelecto por encima del cuidado del cuerpo. A esto se añade que los deportistas ya no son aristócratas que pueden dedicar su hacienda y su dinero a la preparación física, sino que los deportistas se profesionalizan, ganan dinero con esta actividad y compiten, no ya representándose a sí mismos, sino representado a las ciudades y estados. Más adelante, con Filipo de Macedonia se produjo una transformación de la cultura griega y esto repercutió en los Juegos Olímpicos, ya que adquirieron una dimensión universal, convirtiéndose en unos juegos panhelénicos en los que competían deportistas de ciudades de Egipto, Siria o Macedonia, siendo el propio Filipo uno de los participantes de los juegos. Los juegos eran el lugar de 
encuentro de políticos que diseñaban sus alianzas, de artistas que mostraban sus habilidades artísticas y de comerciantes que hacían sus negocios aprovechando la presencia de los espectadores. Durante el Imperio romano algunos emperadores se interesaron por los juegos, como Nerón, que participó en los juegos en la competición dramática y en las carreras de cuadrigas y carros. Sin embargo, los juegos ya no volvieron a tener la aureola heroica de los primeros tiempos y esto, unido al desprecio del cristianismo por este tipo de espectáculos, hizo que los juegos desaparecieran con Teodosio I en el año 394.

Curiosamente, cuando Coubertin se empeña en resucitar los Juegos Olímpicos dotándolos de una dimensión internacional para fomentar la práctica del deporte en las instituciones académicas, escoge el lema latino mens sana in corpore sano, que había sido utilizado por John Hulley en su gimnasio de Liverpool (Young 2005). Hulley fue un gran defensor de la importancia del ejercicio físico y llegó a organizar el primer gran festival olímpico en 1862 en Liverpool. Al barón este lema le pareció muy apropiado, ya que reflejaba las cualidades que debían desprenderse de una buena educación: el ejercicio físico era beneficioso para mantener un espíritu virtuoso. La cita latina, sin embargo, no hace referencia al beneficio que tiene el deporte en el espíritu, ya que cuando Juvenal compone sus sátiras utiliza esta frase para aludir a otra cuestión bien distinta. En la sátira x, 356, el escritor cristiano dice: Orandum est ut sit mens sāna in corpore sānō, aludiendo al hecho de que los cristianos deben rezar por cuestiones importantes como tener un cuerpo y una mente sana, y dirigir sus plegarias a un solo Dios.

\section{LOS ORÍGENES DE LOS JUEGOS OLÍMPICOS EN JAPÓN}

Por la misma época del barón de Coubertin en Japón aparece un hombre con objetivos idénticos a los del aristócrata francés: introducir el entrenamiento físico como parte integral de la educación japonesa. Kanō Jigorō (1860-1938), profesor y director de la Universidad de Educación de Tokio, es quizás más conocido como el inventor del deporte del $j \bar{u} d \bar{o}$, una forma de combate sin armas que combina elementos de koryû bujutsu con técnicas destinadas a llevar el tradicional arte marcial a la era moderna (Amdur 2007). Kanō estaba muy preocupado con la modernización de Japón, y para él la educación física era un tipo de instrucción esencial en la formación de la juventud japonesa. No tenemos que olvidar que Kanō vive en plena época Meiji (1868-1912), un período de expansión para Japón, que entra a formar parte de la esfera internacional con muchos problemas internos, ya que la sociedad feudal japonesa no está preparada para cambiar su forma de vida de la noche a la mañana. Por eso las ideas de Kanō sobre la educación suponen para el país nipón, por una parte, un tipo de formación más completa y universal, y por otra parte, un respeto a la cultura japonesa con la práctica del arte marcial autóctono.

Este educador japonés comparte ideales con Coubertin, aunque el francés va más allá y desea impulsar la educación física de manera global, defendiendo la actividad deportiva como parte esencial del desarrollo cultural y humano a nivel 
internacional. Por eso su empeño en poner en marcha un tipo de competición internacional que motivara a los países a preparar a sus deportistas en niveles altos de exigencia en resultados deportivos. Es importante subrayar que, durante la segunda mitad del siglo XIX y la primera mitad del xx, Europa sufre una tremenda transformación política, económica, social y educativa, que tensiona las relaciones entre los países y entre las clases sociales. Por eso Coubertin defiende su visión global del deporte como una oportunidad para minimizar las tensiones entre los países e intentar buscar la paz a través de la competición deportiva, que a su vez mejora la educación de los individuos, pues los conduce a intentar superarse física, intelectual y moralmente. Su idea fue apoyada sin reservas por los movimientos por la paz en el mundo, y en 1896 se lleva a cabo la primera olimpiada moderna en Atenas con la participación de 14 países (entre los que no figuraban ni España, que debutó en 1900, ni Japón, que lo hizo en 1912), 241 atletas masculinos (ninguno femenino) y nueve deportes. Desde este momento los Juegos Olímpicos han seguido celebrándose cada cuatros ańos (con algunas excepciones) y solo se han suspendido en tres ocasiones debido a los dos grandes conflictos bélicos mundiales: en 1916, 1940 y 1944. Esto no quiere decir que todos los encuentros olímpicos se celebrasen con el espíritu con el que Coubertin los había concebido, ya que fueron muchas las ocasiones de tensiones políticas, raciales y económicas que ensombrecieron algunas actuaciones. Por eso, la suspensión de los juegos en Tokio en el año 2020, debido a la pandemia mundial, constituye una excepción turbadora que nos remonta a esos años de conflicto bélico en los que el espíritu olímpico se desvaneció. Sin embargo, hay un consenso mundial de unanimidad excepcional que incita a seguir con este espíritu de competición que simboliza la posibilidad de paz en un contexto de superación individual y de trabajo en equipo, representando a los diferentes países del mundo.

En 1909, durante una sesión del Comité Olímpico, se conocen, por fin, Kanō y Coubertin, pero no será hasta las Olimpiadas de Estocolmo de 1912 cuando Kanō pase a formar parte del Comité Olímpico Internacional (COI), convirtiéndose en el primer representante asiático, así como fundador del Comité Olímpico Japonés (JOC), del cual fue su primer presidente entre los años 1911 y 1921. Este educador japonés había introducido el jū $\bar{o}$ como parte de la educación de los jóvenes japoneses y convenció a Coubertin de que ese deporte debía formar parte de la competición olímpica. Sin embargo, no será hasta las olimpiadas de 1964 cuando el jūdō entró a formar parte de los Juegos Olímpicos.

Al igual que en Grecia, en Japón los deportes de la antigüedad compartían una serie de características comunes que los hacen diferentes a los deportes tal y como los conocemos en la actualidad (Gutmann 2001: 3). En primer lugar, muchos de los deportes antiguos tenían su origen en los rituales religiosos que se llevaban a cabo para celebrar festivales religiosos en los santuarios sintoístas y en los templos budistas por todo Japón. Sin embargo, intelectuales japoneses apuntan que, aunque este rito tiene su origen en las ceremonias religiosas, anteriormente provenía de un rito agrario (Wakamori 1963:35) en el que las mujeres realizaban una danza ante el emperador para pedir lluvia (Kaneda 1999: 114). Uno de los festivales más famosos es el que aún tiene lugar en el santuario de Kamigamo en Kioto, llamado karasuzumo, en el que se representa la lucha divina que tuvo lugar en Japón en los tiempos 
antiguos, tal como lo recoge el Kojiki (712) (registro de las cosas antiguas), el libro más antiguo existente en japonés, que relata la creación del mundo y varios mitos y leyendas de Japón. Una de las leyendas es la famosa batalla entre el dios Takemika$z u k i$ (dios del trueno y dios del sable), enviado por la diosa Amaterasu (diosa del sol) para pacificar Japón. El dios de la tierra Okuninushi-no Mikoto, aceptó que el país se cediese a los dioses del cielo con la condición de que sus hijos estuvieran de acuerdo con su decisión, pero Takeminakata fue el único hijo de Okuninushi-no mikoto que no quiso entregar el país a los dioses del cielo, por lo que tuvo que enfrentarse a Takemikazuki. Vencido en la lucha, Takeminakata no tuvo otro remedio que aceptar que la tierra fuera gobernada por los dioses del cielo, y este combate sería el origen del sumo (Paz Gutiez 2006).

En segundo lugar, los deportes de la antigüedad, como el yabusame (tiro con arco a caballo), admitían únicamente a hombres de las clases altas, mientras que hoy en día es fundamental que cualquiera que tenga las cualidades necesarias para practicar un deporte pueda hacerlo. Este deporte, por ejemplo, no tiene un origen religioso, sino guerrero. Eran los señores más hábiles los que destacaban en la guerra y se llevaban los honores los que se ejercitaban en esta práctica que luego se convirtió en deporte. Es a partir del siglo XVI, cuando los portugueses generalizan el uso de las armas de fuego en Japón (Brown 1948: 240), que el tiro con arco pasa de ser una forma de combatir en la guerra a una competición deportiva y una ceremonia religiosa. No es que los japoneses no conocieran las armas de fuego, ya que China había introducido en el país vecino un tipo de arma de fuego muy básica llamada teppō (cañón de hierro), que consistía en un tubo metálico sin gatillo ni visor cuyo uso no fue muy extendido. Sin embargo, la introducción de los arcabuces por los portugueses en el siglo XVI (Cabezas 1994) supuso un cambio en la manera de guerrear (Howell 2009). La tercera característica es que en el deporte actual existe una burocratización excesiva que va desde niveles locales hasta la organización de los Juegos Olímpicos, pero en la antigüedad los deportes carecían de este tipo de estructuras de gestión. La especialización sería la cuarta característica que diferencia los deportes en la antigüedad, ya que algunas prácticas como el tiro con arco o el manejo del sable procedían directamente de habilidades en la guerra o eran cualidades especiales derivadas de una profesión. El caso del sable (aunque la traducción que se hace de esta arma japonesa suele ser «espada», dicha traducción no es correcta, ya que la espada japonesa, Nihontō, es generalmente curva, por lo que la traducción correcta en español sería «sable») merece un capítulo aparte, puesto que esta arma en Japón llegó a ser una de las más célebres. Nitobe (1969), en su afán por trasladar la cultura del bushidō (el camino del guerrero) japonés a Occidente, compuso un libro en inglés de carácter propagandístico en 1905, Bushido: The Soul of Japan, definiendo el sable como «el alma del samurái». Sin embargo, el bushidō es un código formulado por Yamaga Sokō (1622-1685), un pensador del período Tokugawa o Edo (1603-1868), que justificó la pervivencia de los samuráis en una época de paz, en la que ya no eran tan necesarias las habilidades guerreras, como servidores de un señor con un alto sentido del giri (deber), el cual implica ejercitarse en unos valores morales excelsos (Varley 2000: 208). En la mitología japonesa los sables eran más importantes que los rayos o las flechas de los dioses griegos, 
romanos o nórdicos, ya que en la mitología de la casa imperial japonesa se cuenta que, cuando la diosa del sol, Amaterasu, envió a su nieto a presidir el archipiélago de Japón, le dio tres regalos divinos conocidos como los Tres Tesoros Sagrados o Sanshu no Jingi, y que consisten en una espada llamada Kusanagi no Tsurugi, una joya o collar de joyas, Yasakani no Magatama, y un espejo, el Yata no Kagami. Se dice que estos tres objetos representan las tres virtudes primarias de Japón: el valor (la espada), la sabiduría (el espejo) y la benevolencia (la joya). El instante en que los príncipes japoneses se convierten en emperadores es cuando reciben los Tesoros Sagrados (Hanso 1928: 63). Por eso el 1 de mayo de 2019 el príncipe Naruhito recibió los Tres Tesoros en una ceremonia a la que solo tuvieron acceso unos pocos privilegiados, como algunos sacerdotes sintoístas, políticos destacados y miembros varones de la Familia Imperial. Estos tesoros son objetos que no se pueden mostrar al público, y solo en algunas noticias que retransmitió la televisión nipona de ese evento, se pudo contemplar parte de los tesoros envueltos en una tela morada. Por seguridad, se suelen guardar por separado en tres lugares diferentes del archipiélago japonés. Como estos objetos forman parte de la leyenda, la ubicación exacta de los mismos no está confirmada. Sin embargo, popularmente se afirma que la espada se encuentra en el Templo Atsuta en Nagoya, la joya en Kōkyo (el Palacio Imperial) en Tokio y el espejo en el Santuario de Ise en Mie.

La quinta característica es la de la reglamentación. En los deportes actuales hay un sinfín de normas que son revisadas anualmente, pero en los juegos antiguos las normas apenas variaban de año en año. La sexta característica es la importancia de lo cuantitativo. Hoy en día todo depende de los números, pero en la época antigua era más importante el camino del autoperfeccionamiento, tal y como lo demuestra la cantidad de textos que se publicaban sobre este tema, que conseguir romper marcas (Nomikos 2021: 83). La obsesión que tenemos hoy día por batir récords era algo totalmente inimaginable en la época antigua.

Los Juegos Olímpicos de 1912 fueron significativos para Japón, aunque el Gobierno no apoyó la iniciativa de enviar atletas a Estocolmo. Sin embargo, Kanō se había forjado una voluntad de hierro y no cejó en su empeño creando una organización propia, Dai Nippon Taiiku Kyokai (asociación educación física del gran Japón) (Imamura 1970), para poder financiar el viaje de los dos únicos atletas que compitieron en Estocolmo. La actuación de los deportistas nipones fue muy pobre y Kanō comprobó allí que había mucho por hacer para que los japoneses llegaran al nivel del resto de competidores internacionales. En las olimpiadas de Los Angeles en 1932, aunque los japoneses temían no ser muy bien recibidos por la invasión japonesa de Manchuria en 1931, lo cierto es que tanto su determinación como su exquisito comportamiento les merecieron las simpatías de sus anfitriones. Además, esas olimpiadas supusieron un gran avance tecnológico para Japón, que consiguió ser el único país en retrasmitir con la NHK las olimpiadas siguiendo un modelo en semidirecto (jikkan hoso), ya que el comentarista iba al estadio y veía el evento deportivo, luego un coche lo llevaba a una emisora y allí recreaba la competición. Su relato se enviaba por cable a San Francisco y a través de una trasmisión de onda corta se trasmitía a Tokio. Todo un esfuerzo tecnológico que se vio culminado en las olimpiadas de 1964 con la retransmisión de las olimpiadas en color. A partir de 
este momento Japón fue ganando confianza en sí misma como nación que podía competir con los mejores, y en 1940 presentó su candidatura para organizar las olimpiadas, y aunque Helsinki parecía una candidatura más apropiada, Tokio se las ingenió para vencer. El comité olímpico contaba con dos representantes japoneses, Kanō y el conde Soyeshima Michimasa, pero hacía falta un tercer candidato y se nombró a Tokugawa Iesato, hijo adoptivo del último shögun (título que ostentaba el jefe de Estado durante el Japón feudal), Tokugawa, Yoshinobu, que llegó a ser director del comité organizador (Hashimoto 1992: 76).

Por desgracia, estos fueron los segundos Juegos Olímpicos que hubo que cancelar por problemas políticos, aunque Kanō no llegó a experimentar ninguna humillación ni decepción porque murió antes de una neumonía, en 1938, después de haber defendido magistralmente la candidatura de Tokio en unas circunstancias bélicas muy complicadas.

\section{LAS OLIMPIADAS EN LAS LETRAS JAPONESAS}

El movimiento olímpico y todo lo que suponen los Juegos Olímpicos han supuesto temas de inspiración que tanto políticos como artistas han utilizado para crear narrativas potentes que enardecen espíritus y levantan pasiones que favorecen el nacimiento o fortalecimiento de un espíritu nacional que se enorgullece de competir al máximo nivel y de vencer. Los Juegos Olímpicos suponen una ventana a través de la cual se puede observar el progreso de una nación y la precepción que se tiene de ella en el resto del mundo. Los escritores encuentran en los Juegos Olímpicos un tema fundamental para describir y narrar el complejo mundo de las emociones y muchos escritores japoneses han desempeñado este papel de observadores de la realidad olímpica y de su conversión a narrativas sugerentes. Una de las primeras narraciones japonesas de los Juegos Olímpicos fue la novela que llegó a ser un bestseller, Orinposu no Kajitsu, The Fruits of Olympus (1940), obra de Hidemitsu Tanaka (1913-1949), atleta japonés que compitió en remo y cuyo éxito no descansa en el relato de una historia de sufrimiento, resiliencia y victoria, ya que él mismo fue un perdedor en los Juegos Olímpicos, sino que su popularidad se basa en el tipo de historia que cuenta a bordo del barco que traslada a los deportistas japoneses de Japón a EE. UU. y la decepción que sufre por no poder estar con la chica de la que se enamora en el barco, ya que las relaciones están prohibidas, y por su incapacidad para expresarse y para combatir la angustia que siente al tener que participar en unos juegos en los que no se siente suficientemente preparado, cuestionando la manera espartana en la que ha sido entrenado. Esta sensación de impotencia y de debilidad en comparación con las fortalezas de los demás atrajo a los jóvenes japoneses, que vieron en la novela su propia impotencia y decepción. Tanaka, además, fue un discípulo aplicado de otro novelista, Dazai Osamu (1909-1948), que le dio muy buenos consejos para culminar su novela. A su vez Dazai sentía adoración por el gran escritor japonés Akutagawa Ryunosuke (1892-1927), cuyo nombre sirvió para denominar los premios literarios más importantes de Japón, y ambos hombres tuvieron un final trágico, ya que ambos culminaron sus vidas suicidándose, hecho que 
influyó mucho en Tanaka, que también acabó quitándose la vida. La obra de Akutagawa rezuma aversión a la naturaleza, a la que describe como un poder irracional, salvaje y dominante que supone un desafío constante a la racionalidad humana. Es famosa su descripción de la vida como unas Olimpiadas organizadas por un grupo de lunáticos (Tsuruta 1999).

El poeta japonés Yaso Saijō (1892-1970), que estuvo presente en los Juegos Olímpicos de Los Ángeles, describió su experiencia en las olimpiadas en un artículo que publicó en el periódico aseverando que los Juegos Olímpicos de Berlín fueron simplemente una obra de teatro en la que Hitler tenía el papel de actor principal y los atletas eran meros secundarios. También menciona que el poeta alemán Franz Sondinger, que recibió la medalla de oro en la competición artística de las olimpiadas de Berlín con su poema «Der Läufer» (El Corredor) (Sondinger 1939), se acercó a él y le dijo que le encantaría poder ir a los juegos de Tokio a escribir poesía igual que Yaso había hecho en Berlín pero que, por desgracia, probablemente no iba a poder hacerlo, ya que tanto Alemania como Japón seguramente estarían inmersos en una olimpiada particular de artillería y de armas automáticas. Por desgracia su pronóstico se cumplió. Yaso Saijō es, hoy en día, un poeta japonés muy conocido, sobre todo por el poema Tomino no Jigoku (El infierno de Tomino) (1919), que circula por las redes de internet como un poema maldito que quien lo recita en voz alta sufre una tragedia. Fue un poeta significativo en su época que estudió en la Sorbona y siguió la huella simbolista de Paul Valéry, con quien mantuvo una buena amistad.

Una vez que la guerra estalló, hubo que esperar unos ańos hasta que Japón pudo volver a formar parte de los Juegos Olímpicos, ya que hasta 1951 no se firmó el tratado de paz de San Francisco, que puso fin a la ocupación japonesa, y al año siguiente se envió de nuevo una delegación de atletas nipones a los juegos de Helsinki de 1952. Desde ese instante, Japón deseó ser sede de los juegos por lo que significaba para el país volver a ser aceptado en la arena internacional desde el punto de vista político, económico y social. Japón necesitaba ser reconocido como un país capaz de estar entre los más grandes e influyentes de la esfera mundial, de ahí que en 1959 en Múnich, se volvió a presentar la candidatura de Tokio para organizar los juegos, compitiendo con ciudades como Detroit, Viena y Bruselas. Finalmente, Tokio salió vencedora y se convirtió en la primera ciudad asiática en organizar los Juegos Olímpicos. Aunque ya se había estado preparando para recibir los juegos en 1940, Tokio había sufrido varias vicisitudes, ya que la II Guerra Mundial fue una guerra de destrucción masiva que supuso la pérdida de millones de seres humanos y de infraestructuras. A esto Japón añade su desmoralización total al perder la guerra después de sufrir enormemente con los efectos devastadores de la bomba atómica.

Sin embargo, todas estas desgracias fueron el acicate definitivo para que Tokio resurgiera de sus cenizas y construyera los trenes más rápidos y modernos del mundo, que se pusieron en funcionamiento tan solo 10 días antes del comienzo de los juegos. Una de las infraestructuras más novedosas fue la construcción del Nippon Budokan, a menudo abreviado simplemente como Budokan (casa de las artes marciales), un estadio cubierto situado en Chiyoda, Tokio, obra del arquitecto japonés Mamoru Yamada, que iba a ser reutilizado en las olimpiadas del 2020. Su estructura es impresionante, con un techo que evoca la ladera del monte Fuji coronada 
por una esfera de oro. Además, se construyeron hoteles y se intentó acondicionar la ciudad para recibir a miles de atletas y miembros del comité olímpico y, aunque no se escatimaron esfuerzos, algunos muy criticados porque se expulsó a parte de la población más pobre para dar una imagen de limpieza y poder económico, Tokio no pudo ofrecer alojamiento a todas las personas que llegaron a la capital nipona, y se llegaron a ofertar más de 1445 camas en casas particulares y en barcos atracados en el puerto de Harumi. Esta situación sirvió de pretexto literario y cinematográfico en EE. UU. para contar historias de Japón desde el país del sol naciente, como lo es la duodécima novela de Ian Fleming, Solo se vive dos veces, que se publicó justo en 1964, año en el que casualmente también muere el autor de la novela que retrata a un James Bond en sus horas más bajas. 007 acaba de perder a su mujer, asesinada por su gran enemigo, y el famoso espía del MI6 se dedica a apostar y dilapidar su dinero jugando en casinos, emborrachándose y convirtiendo su vida en un caos absoluto. Para salvarle de sí mismo, $\mathrm{M}$ decide enviar a James Bond a Japón a una misión. Ian Fleming había viajado a Japón en 1962 para documentarse para su novela. En aquel año le sirvieron de guía el periodista y fotógrafo japonés Torao "Tiger» Sato y el reportero australiano Richard Hughes, que había vivido en Japón en los años 40 y había sido espía del MI6. Ambos fueron la inspiración de los personajes que aparecen en su novela y posteriormente, en la película de 1967 que lleva el mismo nombre, y cuyo guion fue adaptado al cine por Roald Dahl. En el libro de Fleming no hay descripciones exhaustivas sobre Japón, pero sí una pequeña introducción con algunas palabras en japonés para invitar al lector a conocer más en profundidad este país que entonces resultaba exótico y muy hospitalario. El final de la película ofrece a Bond (Sean Connery) la oportunidad de permanecer en Japón apadrinando a un niño japonés y convirtiéndose él mismo en el compañero sentimental de la madre del niño. Otra película que describe muy bien el ambiente que se vivió en Tokio en el año olímpico es Apartamento para tres (1966), una comedia que relata las peripecias del industrial inglés sir William Rutland (Cary Grant), cuando llega a Tokio en viaje de negocios y se encuentra con que la ciudad está abarrotada por la masiva afluencia de turistas con motivo de los Juegos Olímpicos, por lo que le resulta imposible encontrar alojamiento, así que se las compone para compartir apartamento durante unos días con una compatriota británica que tiene un apartamento en Tokio y ha puesto un anuncio en la Embajada para buscar compañeros de piso. Junto a ellos se aloja un miembro del equipo olímpico de Estados Unidos. Tan solo se trata de una comedia divertida que tiene como escenario Tokio durante los juegos y no plantea ningún tema en profundidad, aunque supuso un gran escaparate en el mundo occidental de algunos estereotipos japoneses como su hospitalidad y su modernidad.

Todo esto contrasta con la literatura japonesa que se produce en el momento y que muestra la crisis social y psicológica de una nación que ha sufrido enormemente en la guerra, y que tiene que recuperarse rápidamente para adaptarse a una modernidad totalmente nueva y desconcertante para la población. No podemos olvidar que Japón no hacía mucho que había dejado atrás un largo período de aislamiento. La era Meiji, la época en la que Japón entra tímidamente en la modernidad, comienza en 1868 y, en tan solo un siglo, con una guerra devastadora por medio, Japón emerge ante el mundo como una gran potencia tecnológica con un 
pie en el futuro. Para los que contemplaron Japón por primera vez en 1964, este país les resultó increíble, por su capacidad de armonizar tradición y modernidad en tan poco tiempo. Japón pasó de ser un país desconocido a un país de moda y que, en muchos aspectos, competía y aventajaba a Occidente.

Pero este esfuerzo de cara al exterior también supuso una crisis interna notable, desde un punto de vista psicológico y de identidad nacional. Los japoneses sentían la necesidad de volver a definirse, de saber quiénes eran en este nuevo orden mundial, y esto llevó a los intelectuales japoneses a poner en cuestión qué papel debía jugar Japón, tanto en el prisma nacional como en el internacional. Mientras que en el lado competitivo de las olimpiadas de 1964 Japón se identificó con la victoria del equipo femenino de voleibol, en el ámbito literario se publicaron novelas, algunas de ellas germen de futuros premio Nobel de literatura, que hablan de crisis y pérdida de identidad japonesa.

En su página web, The Olympians, 1964-2020, Roy Tomizawa nos habla de una interesante colección de artículos recopilados por Kodansha en A Literary Writers' Record of the Tokyo Olympics (Tokyo-Olimpic-Bungakusha ni Yoru Tokyo Gorin Zenkiroku), en la que participaron algunos de los autores más famosos del país escribiendo sobre las Olimpiadas de 1964. Entre los autores destacan Mishima Yukio, Agawa Hiroyuki o Ariyoshi Sawako, y lo que es más sorprendente de sus comentarios, aparte de ponderar la hazaña del equipo japonés femenino de voleibol, apodado "The Oriental Witches», que se hizo con el oro frente al equipo soviético (en unos juegos en los que este deporte es admitido como especialidad olímpica), es que se destaca sobre todo la feminidad, la dulzura y la compostura que mostraron las mujeres del equipo, epítome de lo que debía constituir la esencia de una mujer japonesa. La descripción que hace Mishima del equipo es una metáfora de un local japonés atendido por mujeres que se esmeran en servir a sus clientes. Mishima hace comentarios tales como:

Kasai (la capitana del equipo) es una anfitriona maravillosa, ya que se da cuenta casi instantáneamente de si los vasos de los invitados (se refiere a sus rivales) se están vaciando o si alguno de los invitados tiene los músculos rígidos y se ocupa de eso ofreciendo un servicio impecable (VV.AA. 2015: 6).

Incluso Ariyoshi, una novelista muy activa en sus novelas luchando por temas sociales como el sufrimiento de los ancianos (Los años del crepúsculo, 1972), el medioambiente y la contaminación (La compleja contaminación, 1975) o el papel de la mujer en la sociedad (El rio Ki, 1959 o La esposa del Médico, 1966), elogia la compostura femenina que mantiene el equipo japonés, que preconiza que estas mujeres llegarán a ser perfectas esposas:

Las atletas japoneses no han olvidado la elegancia de las mujeres japonesas. Fue una batalla dura y el sudor se desparramaba por el suelo. Tan pronto como lo notaban caer, limpiaban el piso con un paño. Era un espectáculo bonito de ver. En mi interior las aplaudía pensando que serían maravillosas esposas cuando se casaran. Creo que su actitud en el juego también causó una buena impresión de nuestro país. Eran señoritas de buenos modales (VV.AA. 2015: 15). 
Aunque tanto Mishima (Tomizawa, 2019: 235) como Ōe mostraron un gran entusiasmo por los Juegos Olímpicos y la hazaña del equipo femenino de voleibol, las obras que publicaron en ese año tratan de temas que tienen que ver con la búsqueda de la identidad y la crisis personal y nacional de un Japón que se debate entre la modernidad y la tradición. Así, Mishima, que se suicida seis años después de las olimpiadas, publica en 1964 Seda y conciencia (Kinu to meisatsu), una historia sobre la huelga que tuvo lugar en la fábrica de seda Omi Kenshi, cerca de Kioto, en 1954, que duró 106 días y que supuso un importante momento histórico para un Japón cuya economía dependía fuertemente de la exportación de la seda para financiar al ejército y para importar y construir buques de guerra en la era Meiji, y que ahora se veía fuertemente afectado por la especulación del mercado internacional. El título de la novela de Mishima nos recuerda el dicho japonés Kinu to gunkan (Seda y barcos de guerra), que hace referencia a una época de poder y orgullo japonés que se desquebrajó con la derrota de la II Guerra Mundial y las consecuencias de pueblo vencido que tuvo que vivir Japón. La novela es un retrato realista de la situación de la empresa japonesa, que pasa de un modelo paternalista a un modelo económico donde los sindicatos, los bancos y la relación entre el patrón y el obrero hacen tambalearse un sistema de jerarquías rígidas, autoritarias y respetadas. Aunque el libro no tuvo éxito de público, y aunque Mishima había pedido al traductor americano, John Nathan, que la tradujera a inglés, este se negó a traducirla porque le pareció más interesante traducir la novela de Ôe Una cuestión personal, que también se publicó en ese año. El relato de Mishima es un testigo fidedigno de la situación agónica que vivía la sociedad japonesa, que tenía que mostrar al mundo una cara amable y dinámica mientras internamente se torturaba por tener que desprenderse de sus rasgos japoneses en favor de un reconocimiento internacional.

La novela de Ōe Kenzaburō, premio Nobel de literatura en 1994, aunque está basada en la traumática experiencia que vivió el escritor cuando su hijo nació con un problema cerebral y la angustia que vivió antes de decidir someter a su hijo a una operación, también nos habla de la manera en la que la sociedad se enfrenta a sus heridas. El protagonista de la novela, Bird, es un profesor que tiene que enfrentarse a un hijo con una malformación y no sabe cómo hacerlo. La novela es asimismo una metáfora de una nación con muchas cicatrices aún sin sanar y que tiene que renovarse por completo para estar a la altura de las circunstancias, pues, al fin y al cabo, los Juegos Olímpicos eran una oportunidad única para demostrar al mundo que Japón podía enfrentarse a una situación dramática y salir victorioso.

Kawabata Yasunari publicó en 1965 Lo bello y lo triste, su última novela antes de recibir el premio Nobel de literatura en 1968 y antes de su suicidio en 1972. En esta novela el protagonista, un famoso escritor, Oki Toshio, decide proponer a una amante que tuvo hacía tiempo, Otoko, reencontrarse para escuchar los sonidos de las campanas de los templos de Kioto en año nuevo. El encuentro entre ambos y la relación de amor-odio por el abandono de Oki cuando Otoko dio a luz a una niña que murió poco después de nacer es asimismo una metáfora de la intricada interconexión entre los viejos tiempos y los nuevos, entre tradición y modernidad y cómo el inflexible paso del tiempo hace que tengamos que adaptarnos con mayor o menor agrado y resiliencia. 
Por último, Abe Kōbō publica en 1964 El rostro ajeno, una obra que utiliza el accidente que desfigura la cara de un cirujano plástico y su empeño en reconstruirla para recuperar a su mujer, que no puede soportar contemplar su cara desfigurada, como metáfora del cambio que se le impone a Japón y su despegue tecnológico. La obra es una profunda reflexión sobre las consecuencias que puede tener el abuso de la tecnología en el individuo y la enajenación que puede producir en una sociedad que se ve empujada a una carrera frenética por dar una imagen de modernidad que no le da tiempo a asimilar.

Como conclusión de este análisis sobre el espíritu olímpico, desde sus orígenes tanto en Grecia y el mundo occidental como en Japón, bien como un ritual de veneración a los dioses, bien como excelencia de una habilidad bélica, podemos inferir que ha habido una evolución similar en Occidente y en Japón en cuanto al concepto de destreza deportiva y ritual religioso y en cuanto a la característica elitista que solo permitía participar en estos juegos a aquellos pertenecientes a las clases altas, pero difiere en cuanto al protagonismo individual que adquiere en Grecia el participante olímpico, ya que en Japón el éxito deportivo era comunitario y no había un individuo que se llevara los honores. Asimismo, desde sus orígenes, los Juegos Olímpicos griegos y las competiciones deportivas japonesas servían de espacio público para mantener relaciones políticas, estratégicas, comerciales y culturales en un ambiente pacífico y ameno. Esta característica continuó a lo largo del tiempo y hoy en día los Juegos Olímpicos siguen siendo ese espacio en el que los países pueden establecer estrategias mundiales en un escenario de competitividad deportiva y relación fraternal. Por eso también era necesario indagar en la otra cara de los Juegos Olímpicos. Por una parte existe toda una producción literaria sobre los Juegos Olímpicos de Tokio de 1964, que mostraban al mundo un país moderno, en el que la tecnología había dado un salto de gigante, pero la sociedad mostraba otro tipo de sentimientos, mucho más difíciles de clasificar, ya que la organización de estos juegos supuso cambios estructurales en las grandes ciudades, que no siempre eran beneficiosos para la población, y por otra parte la literatura producida en Japón por autores japoneses de la época evidencia que la sociedad aún no estaba madura para el espectacular salto que el país nipón había dado en la escena internacional. Esta reflexión nos deja una vía abierta para analizar y comprender lo que pueda ocurrir en los próximos Juegos Olímpicos que serán organizados por Japón en 2021. 


\section{BIBLIOGRAFÍA}

Amdur, Ellis (2007): Koryū. Escuela Antigua. Ensayos sobre las tradiciones marciales japonesas, Shinden Ediciones S.L.

Brown, Delmer (1948): «The impact of Firearms on Japanese Warfare, 1543-98», The Far Eastern Quarterly vol. 7, n. ${ }^{\circ}$ 3: 236-253.

Cabezas, Antonio (1994): El Siglo Ibérico de Japón. La presencia hispano-portuguesa en Japón (15431643), Valladolid: Servicio de Publicaciones de la Universidad de Valladolid.

Coubertin, Pierre de (1970): The Olympic Idea. Discourses and Essays, Laussane: Editions Internationales Olympiques.

Fleming, Ian (1978): You only Live Twice, London: Vintage Books.

Guttman, Allen y Lee Thompson (2001): Japanese Sports A History, Honolulu: University of Hawaii Press.

Hanso, Tarao (1928): «Symbols of Sovereignty are Treasured Gifts from Sun Goddess», Enthronement of the one hundred twenty-fourth Emperor of Japan, Tokyo: Japan Advertiser.

Наsнiмото, Haruo (1992): Nihon supotsu hososhi, Tokyo: Taishukan shoten,

Howell, David (2009): «The Social Life of Firearms in Tokugawa Japan», Japanese Studies 29 (1): 65-80.

Imamura, Yoshio (1970): Nihon taiikushi, Tokyo: Fumaido.

Jessamyn, Abel (2015): The international Minimum. Creativity and Contradiction in Japan Global Engagement, 1933-1964, Hawai: University of Hawai'i Press.

Junko, Tahara (1992): «Count Michimasa Soyeshima and the Cancellation of the XII Olympiad in Tokyo", International Journal of the History of Sports 9, 3 December: 467-472.

Kaneda, Erin (1999): «Trends in Traditional Women's Sumo in Japan», International Journal of the History of Sport 16, 3 September: 113-119.

Ко̄вō, Abe (1964): The Face of Another, trans. Dale Saunders, New York: Borzoi Book.

Mishima, Yukio (1998): Silk and Insight, trans, Hiroaki Sato, London and New York: Routledge.

Nitobe, Inazo (1969): Bushido: The Soul of Japan, Rutland: Charles E. Tuttle.

Nomiкos, Constantine (2012): Voices of Early Modern Japan, California: ABC-CLIO.

ŌE, Kenzaburō (1969): A Personal Matter, trans. Joan Nathan, New York: Grove Press.

Pastor Muñoz, Mauricio, Miguel Villena Posada y José Aguilera González (eds.) (2008): Deporte y olimpismo en el mundo antiguo y moderno, Granada: Editorial Universidad de Granada.

Paz Gutiez, Eduardo de (2006): Sumō. La lucha de los Dioses, España: Shinden Ediciones Aixa.

Sawako, Ariyoshi (1975): Fukufo Osen (The Complex Contamination), Tokyo: Shinchosa.

Sawako, Ariyoshi (1982): The River Ki, trans. M. Tahara, Ohio: Japanese Women Writers.

Sawako, Ariyoshi (1995): The Twilight Years, trans. M. Tahara, Ohio: Japanese Women Writers.

Sawako, Ariyoshi (2004): The Doctor's Wife, trans. M. Tahara, Ohio: Japanese Women Writers.

Sondinger, Franz (1939): Der Läufer, Hamburg: Hauswedell. 
Tomizawa, Roy (July, 14, 2017). URL: https://theolympians.co/2017/07/14/japans-team-the1964-olympics-womens-volleyball-team-part-4-japans-great-novelists-reflect-on-the-oriental-witches/. (Recuperado el 5 de diciembre de 2020).

Tomizawa, Roy (2019): 1964. The Greatest Year in the History of Japan, Honolulu: Lioncrest.

Tsuruta, Kinya (1999): "The Defeat of Rationality and the Triumph of Mother "Chaos": Akutagawa Ryūnosuke’s Journey», Japan Review núm. 11. Published by International Research Centre for Japanese Studies, National Institute for the Humanities.

Varley, Paul (2000): Japanese Culture, Hawai'i University of Hawai'i Press.

VV.AA. (2015): Tokyo-Olimpic-Bungakusha ni Yoru Tokyo Gorin Zenkiroku, Tokyo: Kodansha.

VV.AA. (2009): Budō: The Martial Ways of Japan, trans. Alexander Bennett, Tokyo: Keirin Nippon Budokan Foundation.

Wakamori, Tarō (1963): Sumō ima mukashi, Tokyo: Kawade shobō shinsha.

Yasunari, Kawata (1996): Beauty and Sadness, trans. Howard Hibbett, New York: Vintage International.

Young, David (2005): «Mens Sana in Corpore Sano? Body and Mind in Ancient Greece», The International Journal of the History of Sport, 22, 1: 22-41. 
